\title{
A comparative study on the landslide susceptibility mapping using evidential belief function and weights of evidence models
}

\author{
Qiqing Wang, Wenping Li*, Yanli Wu, Yabing Pei, Maolin Xing and Dongdong Yang \\ School of Resources and Geosciences, China University of Mining and Technology, Xuzhou 221116, China. \\ ${ }^{*}$ Corresponding author.e-mail: wpligroup@126.com
}

The purpose of this study is to produce landslide susceptibility map of a landslide-prone area (Daguan County, China) by evidential belief function (EBF) model and weights of evidence (WoE) model to compare the results obtained. For this purpose, a landslide inventory map was constructed mainly based on earlier reports and aerial photographs, as well as, by carrying out field surveys. A total of 194 landslides were mapped. Then, the landslide inventory was randomly split into a training dataset; $70 \%$ (136 landslides) for training the models and the remaining 30\% (58 landslides) was used for validation purpose. Then, a total number of 14 conditioning factors, such as slope angle, slope aspect, general curvature, plan curvature, profile curvature, altitude, distance from rivers, distance from roads, distance from faults, lithology, normalized difference vegetation index (NDVI), sediment transport index (STI), stream power index (SPI), and topographic wetness index (TWI) were used in the analysis. Subsequently, landslide susceptibility maps were produced using the EBF and WoE models. Finally, the validation of landslide susceptibility map was accomplished with the area under the curve (AUC) method. The success rate curve showed that the area under the curve for EBF and WoE models were of $80.19 \%$ and $80.75 \%$ accuracy, respectively. Similarly, the validation result showed that the susceptibility map using EBF model has the prediction accuracy of $80.09 \%$, while for WoE model, it was $79.79 \%$. The results of this study showed that both landslide susceptibility maps obtained were successful and would be useful for regional spatial planning as well as for land cover planning.

\section{Introduction}

Landslides, often causing property damage and economic losses and creating high maintenance costs, are dangerous natural hazards in many parts of the world (Lee and Oh 2012). Every year, hundreds of people all over the world lose their lives in landslides; furthermore, there are large impacts on the local and global economy from these events (Yalcin et al. 2011). In China, during the last 60 years, natural hazards associated with landslides caused more than 25,000 human deaths. The average annual death number caused by landslides was more than 400 people, and the annual economic losses emanating from landslides are about US $\$ 50$ million (Sang 2013). In addition, currently tens of millions of people still live under the highrisk threat of landslides (Liu et al. 2013). It is therefore necessary to assess and manage areas that are susceptible to landslides in order to mitigate any damage associated with them (Lee 2004).

Landslide susceptibility maps can be produced by common assessment methods such as probabilistic approach (Lee and Pradhan 2006; Akgun et al.

Keywords. Landslide; susceptibility mapping; evidential belief function (EBF); weights of evidence (WoE); geographic information system (GIS), China. 
2008; Vijith and Madhu 2008; Yilmaz and Keskin 2009; Youssef et al. 2009, 2012; Pradhan and Youssef 2010; Demir et al. 2013; Saponaro et al. 2014; Sujatha et al. 2014), statistical models including logistic regression, bivariate and multivariate models, etc. (Ayalew et al. 2005; Lee and Pradhan 2007; Bai et al. 2010; Bednarik et al. 2010; Choi et al. 2012; Raman and Punia 2012 Grozavu et al. 2013; Ozdemir and Altural 2013; Regmi et al. 2014 Solaimani et al. 2013). In addition, other different methods such as analytic hierarchy process (AHP) (Komac 2006; Yoshimatsu and Abe 2006; Yalcin 2008; Ma et al. 2013; Daneshvar 2014), certainty factor (CF) model(Kanungo et al. 2008, 2011; Sujatha et al. 2012; Devkota et al. 2013; Pradhan and Kim 2014; Wang et al. 2015), artificial neural network model (Prabu and Ramakrishnan 2009; Chauhan et al. 2010; Pradhan and Buchroithner 2010; Park et al. 2013; Tsangaratos and Benardos 2014), index of entropy (IoE) model (Mihaela et al. 2011; Davis and Sims 2013; Devkota et al. 2013; Jaafari et al. 2014; Sharma et al. 2015), fuzzy approach (Kanungo et al. 2008; Ercanoglu and Temiz 2011; Suh et al. 2011; Guettouche 2013; Sharma et al. 2013), etc., have also been applied to prepare landslide susceptibility maps. Every assessment model for landslide susceptibility has its advantages and drawbacks; hence, there is no agreement on either the models or the scope of susceptibility map production (Duman et al. 2006; Ma et al. 2013). Therefore, assessment methods for higher precision evaluation need to be developed (Ma et al. 2013). In this paper, two models, including evidential belief function (EBF) and weights of evidence (WoE) were used to assess landslide susceptibility in a landslide-prone area located in the southwest of China. In order to find the better model that is more accurate in landslide susceptibility mapping in the study area, both models were developed, applied, and verified.

\section{The study area}

The selected study area, shown in figure 1, extends to about $1692 \mathrm{~km}^{2}$ and belongs to Daguan County of Yunnan, China. This site lies between latitudes $27^{\circ} 36^{\prime}-28^{\circ} 15^{\prime} \mathrm{N}$ and longitudes $103^{\circ} 43^{\prime}-104^{\circ} 07^{\prime} \mathrm{E}$ and is located in the northern edge of the YunGui plateau buffer area. The altitude of the area ranges from 523 to $2773 \mathrm{~m}$ asl. The terrain disparity of the area is notable, which takes appearance of higher in the north and south area and lower in the middle. The climate in the study area belongs to the semi-tropical monsoon, with high temperature climate summers and a rainy season normally lasting from June to September. The temperature varies between $-6^{\circ}$ and $40^{\circ}$, and the mean annual rainfall is around $1140 \mathrm{~mm}$ based on the records from the China Meteorological Administration. Main streams in the study area include five main rivers. These rivers and their tributaries form dentritic drainage system due to topographical and geological features of the area. In this area, the traffic is convenient. Up to now, the County road mileage is about $1547 \mathrm{~km}$. The population of the County was about 281,900 in the year 2011. This site is one of the frequent landslide occurrence areas in China due to the coupling effects of special geological and climatic conditions and the influences of human engineering activities. In total, 194 landslides were identified and mapped in the study area. Of these, 156 landslides are rotational earth slides, while 38 landslides are earth flow (Sun 2007). The largest landslide encompasses about $1.82 \mathrm{~km}^{2}$, and the smallest one covers approximately $2450 \mathrm{~m}^{2}$. In addition, most of the landslides occurred after heavy rainfall in the region.

\section{Data used}

\subsection{Landslide inventory map}

Historic information on landslide occurrences is considered as the fundamental part of the landslide hazard studies, which give shrewdness into the frequency, volumes, damage, and types of the landslide phenomena (Van Westen et al. 2006; Regmi et al. 2014; Youssef et al. 2014). Therefore, landslide occurrences in the past and present are keys to future spatial prediction; a landslide inventory map, providing the basic information for evaluating landslide hazards or risk, is a pre-requisite for such a study (Guzzetti et al. 1999; Regmi et al. 2014). Accurate collection of the data related to landslides is very important for landslide susceptibility analysis. In this study, the landslide inventory map of the region was prepared by using 1:50,000 scale aerialphoto interpretation and extensive field surveys. Besides, the historical landslide records obtained from the internet and published literature were also used (Sun 2007; Yang 2014). A total of 194 landslides were identified and mapped (figure 1). From these, $136(70 \%)$ landslides were randomly selected as training data and the remaining $58(30 \%)$ landslides were kept for validation purposes (Lee and Oh 2012; Pourghasemi et al. 2012a, b; Zare et al. 2013; Youssef 2015). In this study, all data layers were transformed in raster format with pixel size of $30 \mathrm{~m} \times 30 \mathrm{~m}$, hence the area grid was 2515 rows by 1503 columns with a total of $1,880,85$ pixels.

\subsection{Conditioning factors}

Identification of suitable conditioning factors in a certain area requires prior knowledge of the 


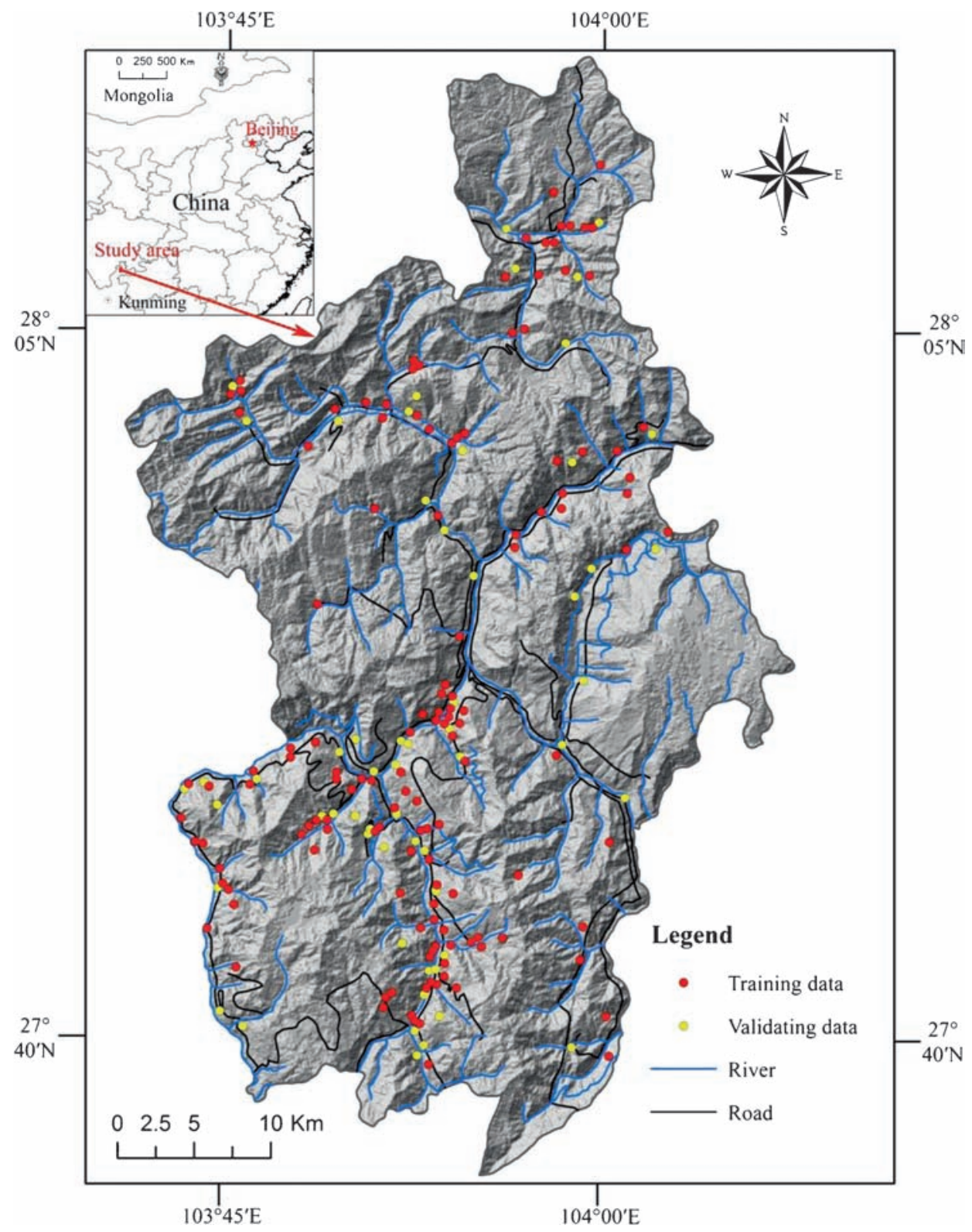

Figure 1. The study area with landslide locations.

landslides (Guzzetti et al. 1999; Ma et al. 2013). In this study, 14 landslide conditioning factors (slope angle, slope aspect, general curvature, plan curvature, profile curvature, altitude, distance to rivers, distance to roads, distance to faults, lithology, NDVI, STI, SPI, and TWI) were chosen to assess the landslide susceptibility of the study area. These factors fall under the category of preparatory factors, responsible for the occurrence of landslides in the region for which pertinent data can be collected from available resources, as well as, from the field surveys.

Slope angle, frequently used in preparing landslide susceptibility maps, is a major parameter in the assessment of slope stability since land sliding is directly related to slope angle (Lee and Min 2001; Saha et al. 2005; Yalcin et al. 2011). The slope map of the study area was prepared from the $30 \mathrm{~m} \times 30 \mathrm{~m}$ digital elevation model (DEM) collected from the Advanced Space-borne Thermal Emission and Reflection Radiometer (ASTER) using ArcGIS 10.0 (ESRI Inc., Redlands, CA, USA) and was classified into seven categories (figure 2a), considering the steepness of the terrain (Kayastha et al. 2013a).

The slope aspect is also considered as an important factor in landslide susceptibility studies since slope aspect is related to the physiographic trends and the main precipitation direction (Ercanoglu and Gokceoglu 2002; Regmi et al. 2014). The aspect of the study area was divided into nine directional classes as flat $(-1)$, north $\left(337.5^{\circ}-360^{\circ}, 0^{\circ}-22.5^{\circ}\right)$, northeast $\left(22.5^{\circ}-67.5^{\circ}\right)$, east $\left(67.5^{\circ}-112.5^{\circ}\right)$, southeast $\left(112.5^{\circ}-157.5^{\circ}\right)$, south $\left(157.5^{\circ}-202.5^{\circ}\right)$, southwest 

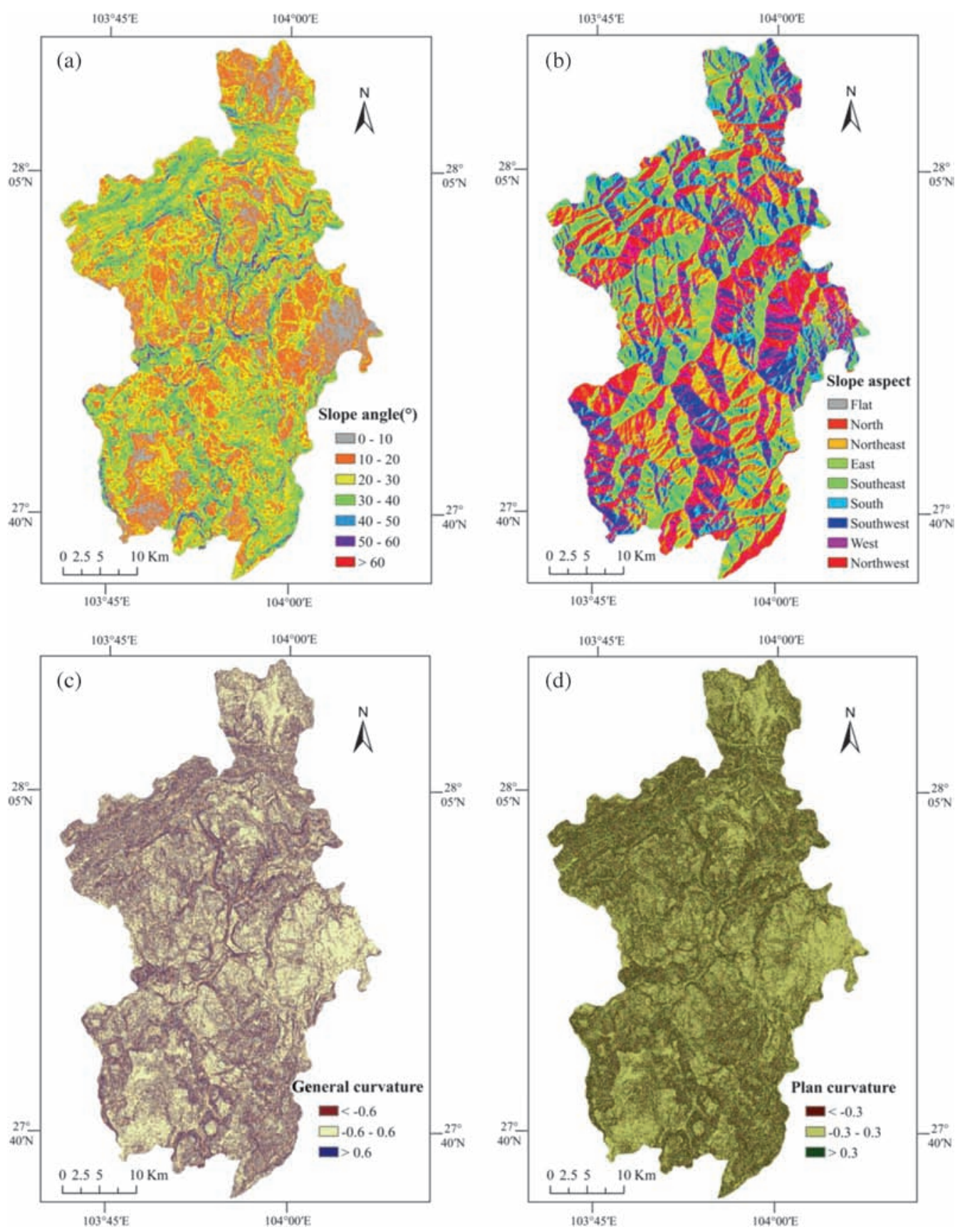

Figure 2. Landslide conditioning factors of the study area: (a) slope angle, (b) slope aspect, (c) general curvature, (d) plan curvature, (e) profile curvature, (f) altitude, (g) distance to rivers, (h) distance to roads, (i) distance to faults, (j) lithology, (k) NDVI, (l) STI, (m) SPI, and (n) TWI.

$\left(202.5^{\circ}-247.5^{\circ}\right)$, west $\left(247.5^{\circ}-292.5^{\circ}\right)$, and northwest $\left(292.5^{\circ}-337.5^{\circ}\right)$ (figure $\left.2 \mathrm{~b}\right)$.

The curvature values represent the morphology of the topography (Devkota et al. 2013). General curvature, defined as the rate of change of slope degree or aspect, has been argued to affect slope stability. The characterization of slope morphology and flow can be analyzed with the help of the general curvature map (Nefeslioglu et al. 2008). Plan curvature influences the convergence and divergence of flow across a surface and profile curvature affects the acceleration and deceleration of downslope flows and, as a result, influences erosion and deposition (Kannan et al. 2013; Pourghasemi et al. 2013; Kritikos and Davies 2014). In this study, the general curvature, plan curvature and profile curvature were derived from the DEM in ArcGIS 10.0 and were divided into three classes, respectively (figure $2 \mathrm{c}, \mathrm{d}, \mathrm{e}$ ).

Altitude or elevation is another frequent conditioning factor for landslide susceptibility analysis. Generally, the landslides have more tendency to occur at higher elevations (Ercanoglu et al. 2004; Devkota et al. 2013). In the study area, the 

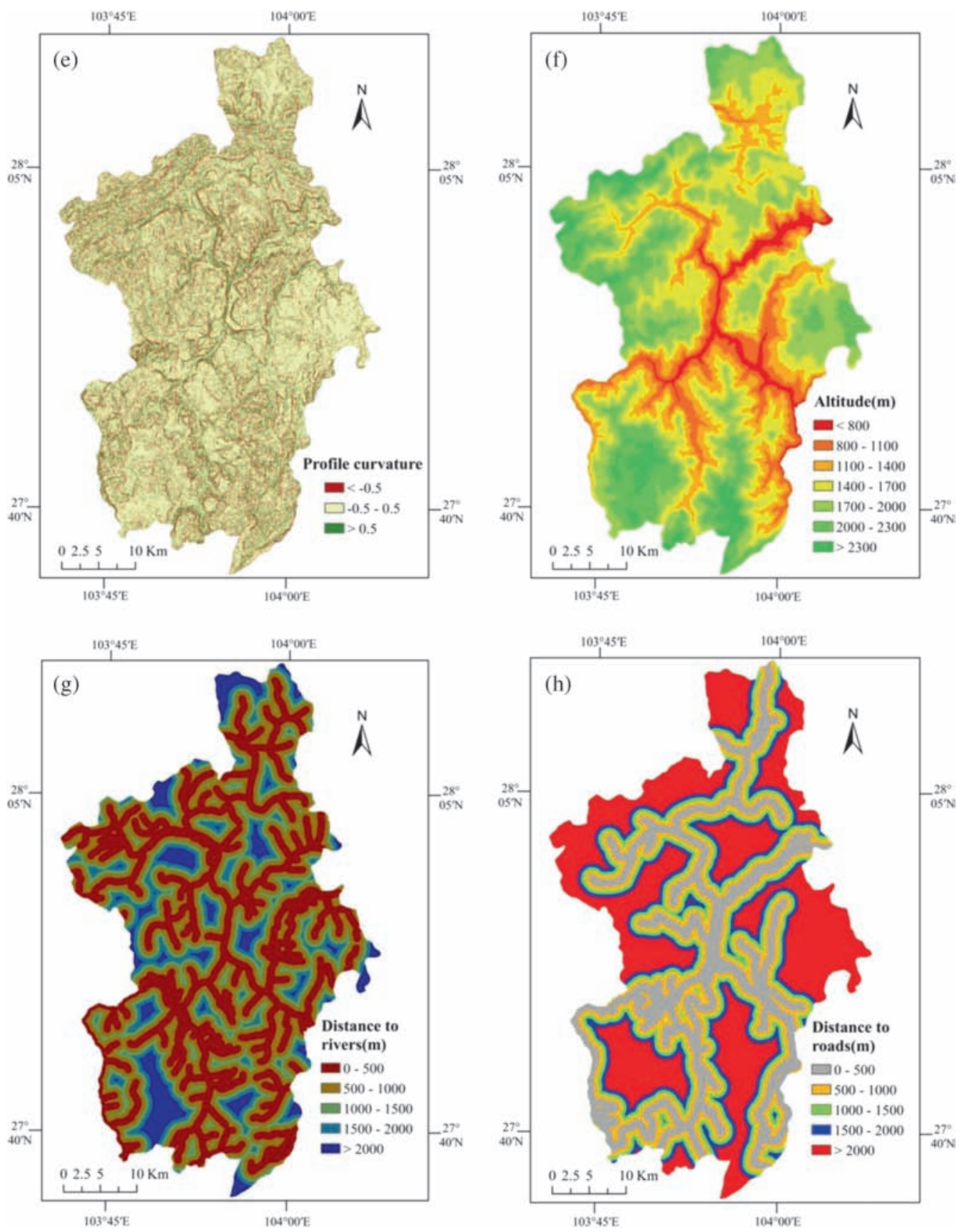

Figure 2. (Continued.)

elevation values were divided into seven categories using an interval of $300 \mathrm{~m}$ (figure 2f).

Runoff plays an important role as a conditioning factor for landslide occurrences (Devkota et al. 2013). The closeness of the slope to drainage structures is another important factor for landslide susceptibility analysis. In the present study, the distance to rivers map was divided into five categories (figure $2 \mathrm{~g}$ ).

The distance to roads has been considered as one of the most important anthropogenic factor influencing landslide occurrence that can be the cause of cut slope creations through construction of roads that disturbs the natural topology and affects the stability of the slope (Pourghasemi et al. 2012a; Devkota et al. 2013; Demir et al. 2013). In the present study, five different buffer zones were created within the study area to determine the degree to which the roads affected the slopes (figure $2 \mathrm{~h}$ ).

The distance to faults was also a necessary parameter in the susceptibility analysis. Commonly, geological fault is responsible for triggering a large number of landslides because of the tectonic breaks that usually decrease the rock strength (Qiao et al. 2014). In this study, five different buffer zones of the distance to faults were prepared from geological maps using the Euclidean distance interpolation method (figure 2i). 

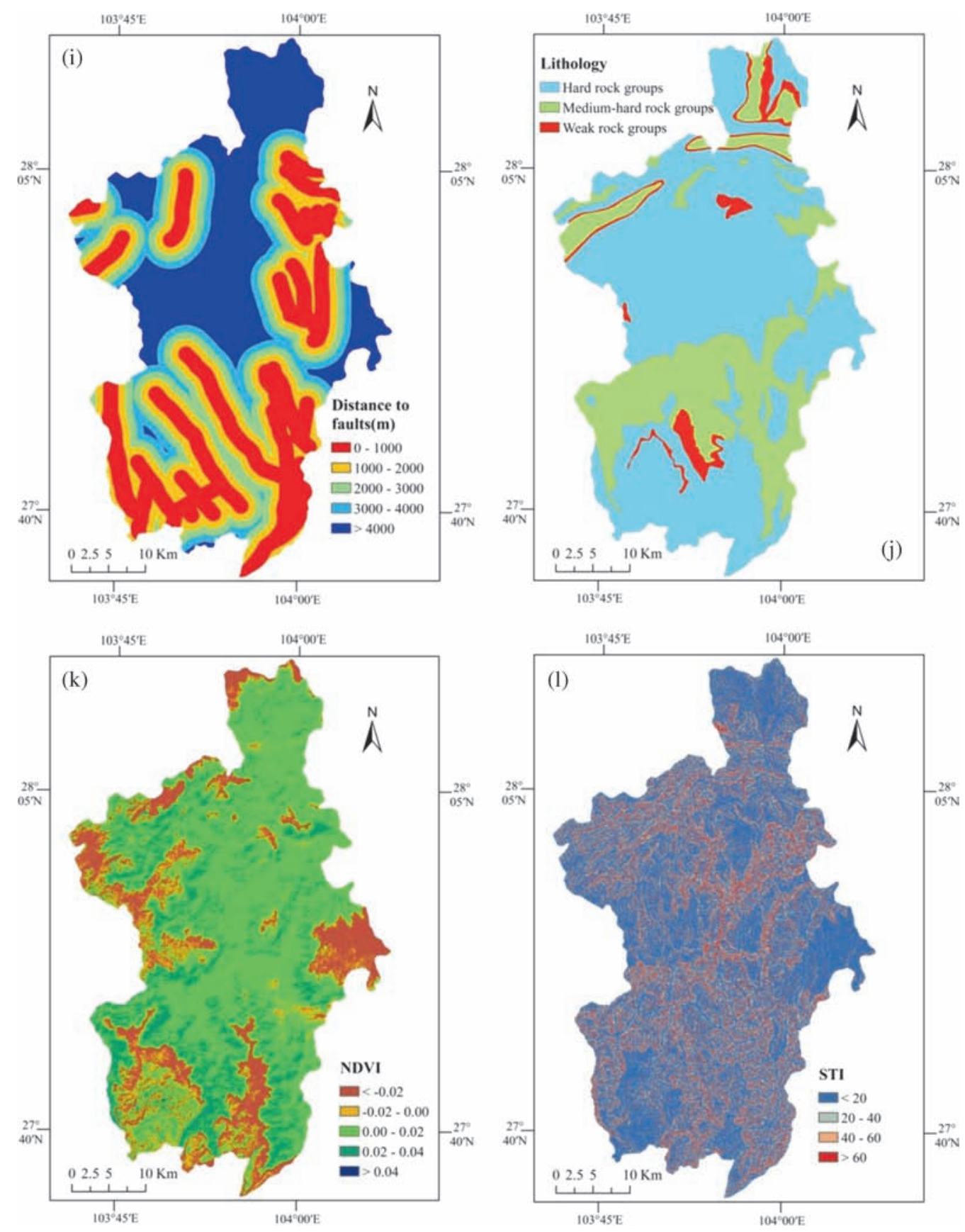

Figure 2. (Continued.)

In general, different lithological units have different landslide susceptibility values, which can provide important information regarding landslide susceptibility of a region (Yalcin and Bulut 2007; Pourghasemi et al. 2012b). Therefore, lithology is also one of the most common determinant factors in landslide susceptibility analysis. Based on the geology database, types of lithology were extracted and all rock masses were divided into three categories, viz., hard rocks, medium-hard rocks, and weak rocks (figure $2 \mathrm{j}$ ). Among them, hard rocks include limestone, dolomite, sandy dolomite, sandstone and basalt; the medium-hard rocks consist of argillaceous dolomite and silty sandstone, and limestone and dolomite interbedding; the weak rocks include argillaceous dolomite with intercalation of shale, mudstone, siltstone mixed mudstone and shale, shale with intercalation of coal, coal, strong weathering rocks and soil.

The NDVI is often considered as a conditioning factor in landslide susceptibility mapping. Its value denotes areas of vegetation in an image (Youssef 2015). In this study, NDVI map was obtained from Landsat satellite image and five classes of the NDVI were extracted as shown in figure $2(\mathrm{k})$.

The sediment transport index (STI) is often used to reflect the erosive power of the overland 

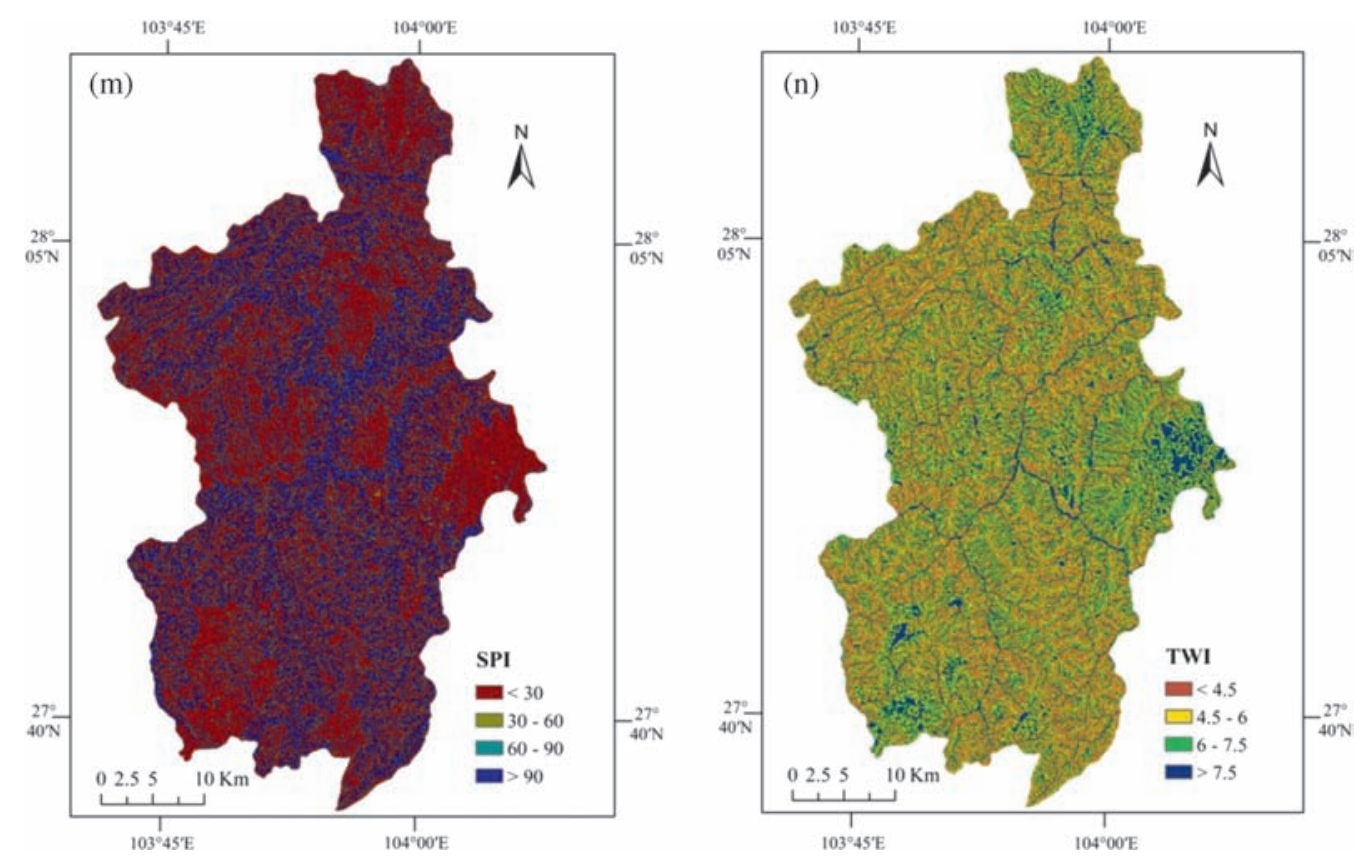

Figure 2. (Continued.)

flow (Pourghasemi et al. 2012a). STI is defined in equation (1) as:

$$
\mathrm{STI}=\left(\frac{A_{S}}{22.13}\right)^{0.6}\left(\frac{\sin \beta}{0.0896}\right)^{1.3}
$$

where $A_{S}$ is the specific catchment area $\left(\mathrm{m}^{2} / \mathrm{m}\right)$, and $\beta$ the slope gradient. In the present study, the STI was calculated as shown in figure 2(l).

The stream power index (SPI), a compound topographic attribute, is often considered as a conditioning factor in landslide susceptibility analysis (Pourghasemi et al. 2012a, b; Devkota et al. 2013; Park et al. 2013; Pradhan and Kim 2014; Saadatkhah et al. 2014). It is a way of measuring the erosive power of water flow based on the assumption that discharge is proportional to the specific catchment area (Conforti et al. 2011). The SPI is expressed as $\mathrm{SPI}=A_{S} \times \tan (\beta)$, where $A_{S}$ is the specific catchment area and $\beta$ is the local slope gradient measured in degrees (Moore et al. 1988; Park et al. 2013). In this study, the SPI map was classified into four classes (figure $2 \mathrm{~m}$ ).

The topographic wetness index (TWI) is another important topographic factor within the runoff model. It describes the effect of topography on the location and size of saturated source areas of runoff generation (Pourghasemi et al. 2012a; Regmi et al. 2014). TWI is calculated as: $\operatorname{Ln}\left[A_{S} / \tan (\beta)\right]$, where $A_{S}$ is the specific catchment area of each cell and $\beta$ represents the slope gradient (in degrees) of the topographic heights (Moore et al. 1988; Regmi et al. 2014). In this study, the TWI was calculated as shown in figure $2(\mathrm{n})$.

\section{Methodology}

\subsection{Evidential belief function (EBF) model}

The Dempster-Shafer theory of evidence, proposed by Dempster (1967) and developed by Shafer (1976), is a generalization of the Bayesian theory of subjective probability. The main advantage of the Dempster-Shafer theory is that it has the ability to combine the beliefs from several sources of evidence and the relative flexibility to accept uncertainty (Thiam 2005; Bui et al. 2012). The DempsterShafer theory of evidence provides a framework for the estimation of EBFs according to Dempster's rule of combination (Liu et al. 2015). The EBFs are compound of $\mathrm{Bel}$ (degree of belief), Dis (degree of disbelief), Unc (degree of uncertainty) and Pls (degree of plausibility), each in the range of 0 and 1 (Althuwaynee et al. 2012; Amiri et al. 2014). Bel and $\mathrm{Pls}$ represent the upper and lower bounds of the probability, respectively, for the suggestion (Awasthi and Chauhan 2011; Althuwaynee et al. 2012). Unc, representing the ignorance, is the difference between the belief and the plausibility. Dis is the belief of the suggestion being untrue based on given evidence (Bui et al. 2012; Awasthi and Chauhan 2011; Althuwaynee et al. 2012). Dis $=1-$ $P l s$ (or $1-U n c-B e l$ ). Therefore, the sum Bel+ $D i s+U n c=1$. For cases of $C_{i j}$ with no landslide occurrence demonstrating that $\mathrm{Bel}=0$, Dis is reset to 0, even if Dis is not (Carranza et al. 2008; Al-sharif and Pradhan 2015).

By overlaying the landslide inventory map on every thematic map of landslides conditioning 
factors, we determined the number of pixels with landslides and pixels with no-landslides for each factor class. Suppose an exploration area $(C)$ consists of $N(C)$ total number of unit cells or pixels and landslides $(L)$ occur in $N(L)$ number of pixels. Suppose, further that $C_{i j}(i=1,2, \ldots, n ; j=$ $1,2, \ldots, m)$ is the $j$ th class of the $i$ th landslide conditioning factor and $N\left(C_{i j}\right)$ is the total number of pixels in the class $C_{i j}$. Also, $N\left(L \cap C_{i j}\right)$ represents the number of landslide pixels in $C_{i j}$ (Bui et al. 2012; Liu et al. 2015). The data driven estimation of EBF could be obtained by (Bui et al. 2012; Liu et al. 2015):

$$
B e l_{C_{i j}}=\frac{W_{C_{i j} L}}{\sum_{j=1}^{m} W_{C_{i j} L}}
$$

where

$$
\begin{gathered}
W_{C_{i j} L}=\frac{N\left(L \cap C_{i j}\right) / N(L)}{\left[N\left(C_{i j}\right)-N\left(L \cap C_{i j}\right)\right] /[N(C)-N(L)]} \\
D i s_{C_{i j}}=\frac{W_{C_{i j} \bar{L}}}{\sum_{j=1}^{m} W_{C_{i j} \bar{L}}}
\end{gathered}
$$

where

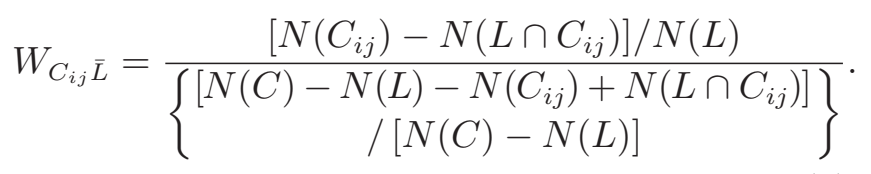

The $W_{C_{i j} L}$ in equation (3) is the ratio of the conditional probability that landslide $(L)$ exists given the presence of $C_{i j}$ to the conditional probability that landslide $(L)$ exists given the absence of $C_{i j}$. The $W_{C_{i j} \bar{L}}$ in equation (5) is the ratio of the conditional probability that landslide $(L)$ does not exist given the presence of $C_{i j}$ to the conditional probability that landslide $(L)$ does not exist given the absence of $C_{i j}$. The $W_{C_{i j} L}$ is the weight of $C_{i j}$ that supports the belief that landslides are more present than absent, while the $W_{C_{i j} \bar{L}}$ is the weight of $C_{i j}$ that supports the belief that landslides are more absent than present. The formulas for combining EBFs of two landslide conditioning factors $\left(C_{1}\right.$, $C_{2}$ ), according to an OR operation, are as follows (Carranza et al. 2005; Bui et al. 2012):

$$
\begin{gathered}
B e l_{C_{1} C_{2}}=\frac{\operatorname{Bel}_{C_{1}} \operatorname{Bel}_{C_{2}}+B e l_{C_{1}} U n c_{C_{2}}+B e l_{C_{2}} U n c_{C_{1}}}{1-B e l_{C_{1}} D i s_{C_{2}}-D i s_{C_{1}} B e l_{C_{2}}} \\
D i s_{C_{1} C_{2}}=\frac{D i s_{C_{1}} D i s_{C_{2}}+D i s_{C_{1}} U n c_{C_{2}}+D i s_{C_{2}} U n c_{C_{1}}}{1-B e l_{C_{1}} D i s_{C_{2}}-D i s_{C_{1}} B e l_{C_{2}}} \\
U n c_{C_{1} C_{2}}=\frac{U n c_{C_{1}} U n c_{C_{2}}}{1-B e l_{C_{1}} \operatorname{Dis}_{C_{2}}-\operatorname{Dis}_{C_{1}} \text { Bel }_{C_{2}}}
\end{gathered}
$$

Integrated EBF of the remaining landslide conditioning factors are implemented one after another by using equations $(5,6$, and 7$)$. The calculation of $\mathrm{Bel}$, Dis, Unc, and Pls for each class of conditioning factor are shown table 1. Finally, the landslide susceptibility index $\left(L S I_{B e l}\right)$ is calculated by the summation of all values of $\mathrm{Bel}$ for each factor contributing to landslide occurrence and this formula is as follows (Pradhan et al. 2014):

$$
L S I_{B e l}=\sum_{i=1}^{n} B e l_{i}
$$

where $n$ is the number of conditioning factors.

\subsection{Weights of evidence (WoE) model}

In this study, weights-of-evidence (WoE) model was used for the landslide susceptibility mapping. The method is based on Bayesian probability framework, which was originally developed for mineral potential assessment (Bonham-Carter et al. 1988; Agterberg et al. 1993; Dahal et al. 2008). Currently, several authors have applied the weights-ofevidence method to landslide susceptibility mapping using the GIS (Dahal et al. 2008; Sharma and Kumar 2008; Ghosh et al. 2009; Ozdemir and Altural 2013). Detailed description of the mathematical formulation of the method was given in several research papers (Bonham-Carter et al. 1988; Van Westen 2000; Lee et al. 2002; Dahal et al. 2008; Regmi et al. 2010). Weights for each landslide predictive factor $(B)$ are calculated based on the presence or absence of landslides $(D)$ within the different classes of a conditioning factor (Kayastha et al. 2012):

$$
\begin{aligned}
& W_{i}^{+}=\ln \frac{P\{B \mid D\}}{P\{B \mid \bar{D}\}} \\
& W_{i}^{-}=\ln \frac{P\{\bar{B} \mid D\}}{P\{\bar{B} \mid \bar{D}\}}
\end{aligned}
$$

where $W^{+}$and $W^{-}$are the weights for the presence or absence of landslides within a certain class of a conditioning factor map, $P(B \mid D)$ is the conditional probability of $B$ occurring given the presence of $D, B$ is a class of the particular predictive variable and the $\bar{B}$ represents the absence of the class and/or of the event (landslide). $D$ is the presence of landslide, and $\bar{D}$ is the absence of a landslide (Dahal et al. 2008; Kayastha et al. 2012). $W_{i}^{+}$ was used to indicate the importance of the presence of parameter for the occurrence of landslides. If it has a positive value, presence of the factor is favourable for the occurrence of landslides and if $W_{i}^{+}$is negative, it is not favourable. Similarly, 
$W_{i}^{-}$was used to evaluate the importance of the absence of a parameter for the occurrence of landslides (Sharma and Kumar 2008). The difference between the two weights is known as the weight contrast, $C\left(C=W_{i}^{+}-W_{i}^{-}\right)$, which provides a measure of the strength of correlation between the predictable variable and landslides (Armaş 2012). The standard deviation of contrast, $S(C)$, is calculated from the variances of the weights, viz., (Ghosh et al. 2009): $S(C)=\sqrt{S^{2}\left(W^{+}\right)+S^{2}\left(W^{-}\right)}$. The Studentised contrast, $C / S(C)$, gives a measure of confidence (Kayastha et al. 2012).

\section{Results and discussion}

\subsection{Evidential belief function (EBF) model}

The range of correlation between conditioning factors and incidences of landslide depends on the $\mathrm{Bel}$ value. Higher the $\mathrm{Bel}$ value, stronger the relationship between the factors and the incidence occurrence probability and vice versa (Pradhan et al. 2014). It can be observed from table 1 that slope angles in the range of $50^{\circ}-60^{\circ}$ have the high $\mathrm{Bel}$ and low Dis values, indicating the highest probability of landslides. In the case of slope aspect, high $\mathrm{Bel}$ and low Dis values for southwest and west facing slopes indicate that these categories have positive spatial associations with landslides. They are followed by the northwest, southeast and north categories. In the case of relationship between landslide occurrence and general curvature, plan curvature and profile curvature, the results show that as their values increase, the landslide probability decreases. For altitude, there are high $\mathrm{Bel}$ and low Dis values for the classes 800-1100 m and 1100-1400 m, indicating high probability of landslide occurrence. In case of distance from rivers, the highest probability for landslide occurrence is within distances less than $500 \mathrm{~m}$. There is very low probability of landslide occurrence at distances of 1500-2000 m. In case of distance from roads, the closer the road, the greater is the landslide probability. At a distance of $<500 \mathrm{~m}$, the $\mathrm{Bel}$ value is 0.41 , showing a high probability of a landslide. The $\mathrm{Bel}$ value is lowest at a distance $>2000 \mathrm{~m}$ and this indicates a low probability. For distance to faults, the $\mathrm{Bel}$ and Dis values show that the classes 2000-3000 m, and 3000-4000 $\mathrm{m}$ have high $\mathrm{Bel}$ and low Dis values, indicating high probability of landslide occurrence. Values of $\mathrm{Bel}$ for the remaining categories are relatively low and indicate low probability of landslides. The main reason for this result is that other conditioning factors, such as slope, altitude, distance to rivers, distance to roads, and lithology, play a more important role in landslide occurrence compared to the distance to faults in this study area. For the lithology, it can be seen that the weak rock groups has high $\mathrm{Bel}$ and low Dis values. This indicates a higher probability of landslide occurrence than in other lithologies. The $\mathrm{Bel}$ value for NDVI showed that classes of $0.02-0.04,>0.04$ have the most effect on the occurrence of landslides with high value of 0.61 . The relation between STI and landslide probabilities showed that $>60$ class has the highest value of $\mathrm{Bel}(0.3)$, and for SPI, the class of 30-60 shows a high Bel value (0.29). Similarly, for TWI, the highest $\mathrm{Bel}$ value (0.28) was obtained for the class of $<4.5$.

In this study, the final calculated landslide susceptibility index (LSI) values of the area for EBF model, range from about 1.950 to 4.806 . Using the natural breaks method in ArcGIS 10.0, the landslide susceptibility map generated was reclassified into five classes: very low, low, moderate, high, and very high (figure 3). According to this model, the very low and low susceptibility areas are $17.65 \%$ and $26.60 \%$, respectively. Meanwhile, the percentages of moderate, high, and very high susceptibility areas are $23.47 \%, 21.26 \%$, and $11.03 \%$, respectively. In addition, $40.21 \%$ and $38.66 \%$ of the total landslides fall in the very high and high susceptibility zones, respectively. Moderate, low, and very low susceptible zones represent $15.98 \%, 4.1 \%$, and $1.03 \%$ of the landslides, respectively (figure $5 \mathrm{a}$ ).

\subsection{Weights of evidence (WoE) model}

Using the weights of evidence model, the spatial relationship between landslide-occurrence and factors influencing landslides was assessed (table 1). The relationship between landslide occurrence and slope angle shows how gentle slopes have a low probability of landslide occurrence because of the generally lower shear stresses. The slope of $50^{\circ}-60^{\circ}$ is shown to have the highest Studentized contrast, indicating that this category is most susceptible to landslides. In the case of slope aspect, slope class $-16^{\circ}$ shows a good positive relationship with the occurrence of landslides. The slope aspects of west are more susceptible to landslides. This is likely due to the orientation of the main valley, which makes the slopes with west aspect drier while resulting in less natural vegetative cover and making the slopes unstable. The results show that general curvature $>0.6$, plan curvature $>0.3$ and profile curvature $<-0.5$ have high influence in triggering landslides. In the case of relationship between landslide occurrence and altitude, class of 1100-1400 m has the highest Studentized contrast, indicating a high probability of landslide occurrence. In the case of distance from rivers, the weight value is higher in the class $0-500 \mathrm{~m}$, indicating a higher probability of landslides occurrence. The distance from roads 


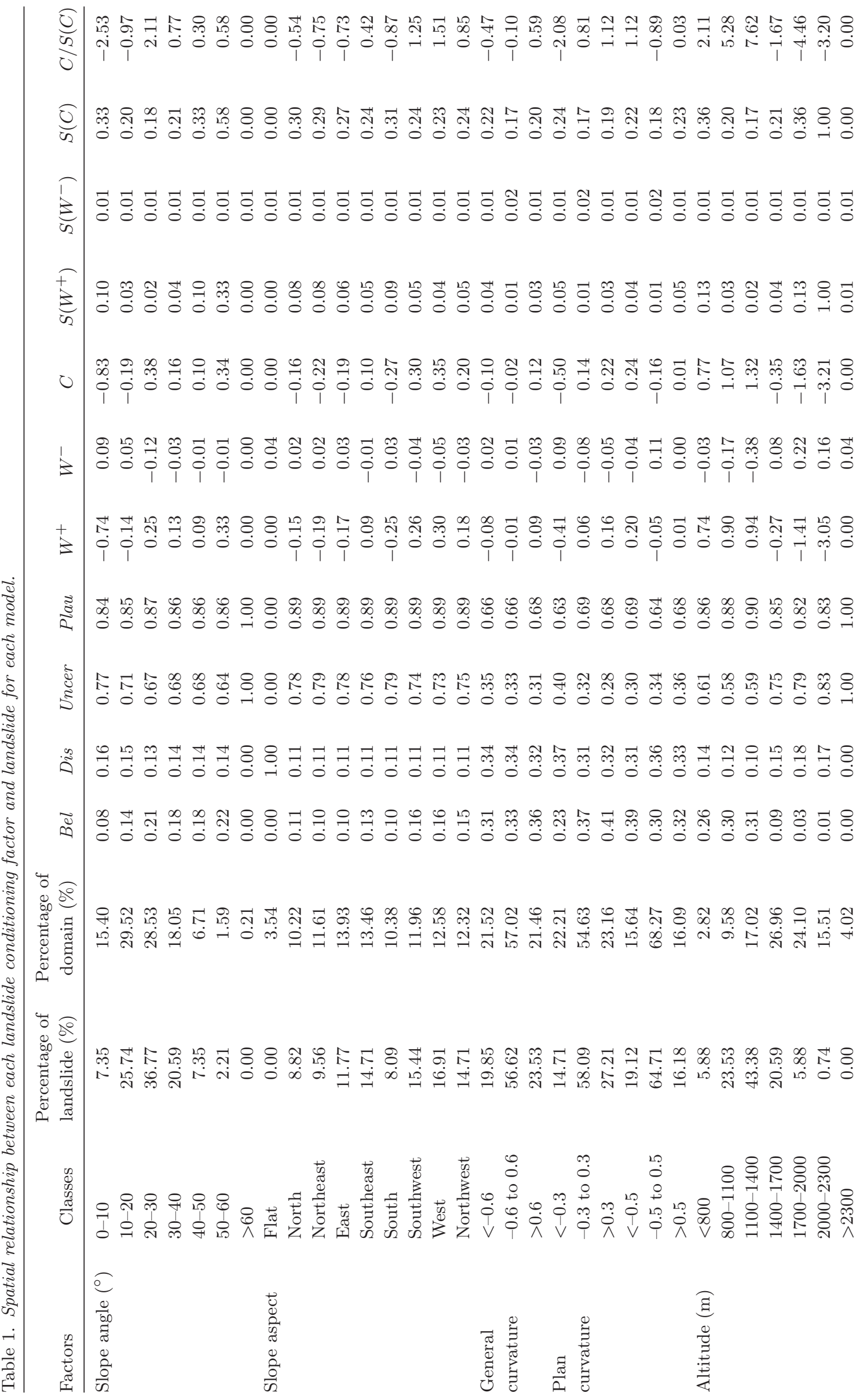




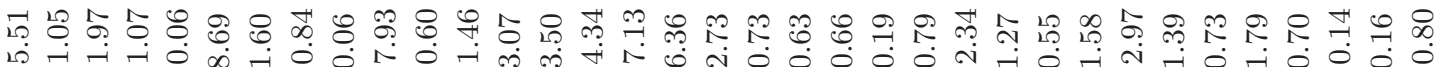
ம

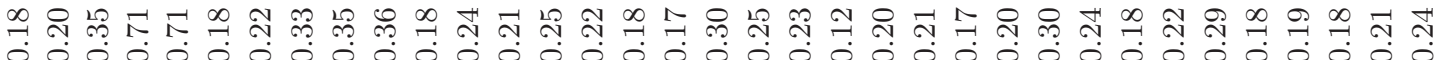

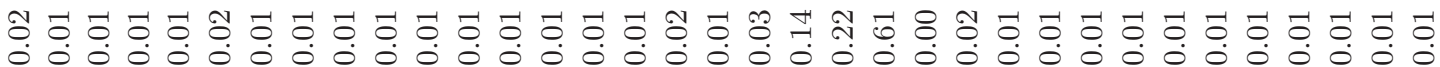

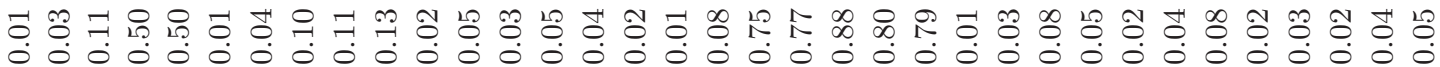

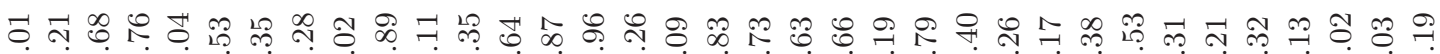

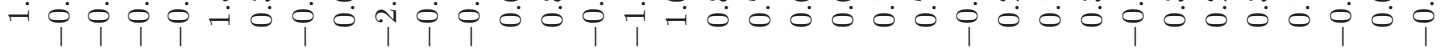

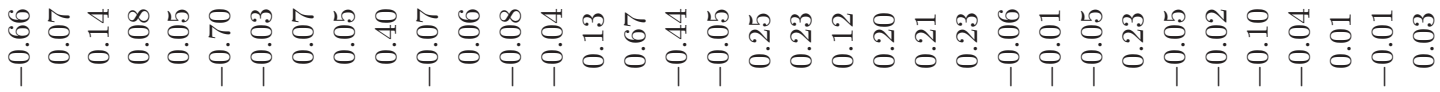

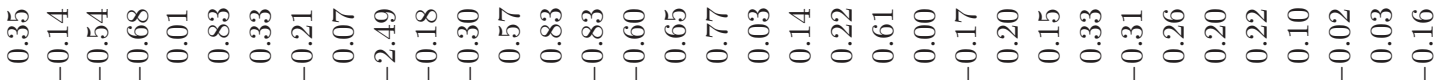

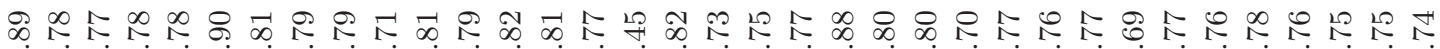

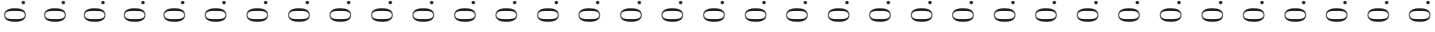

둔

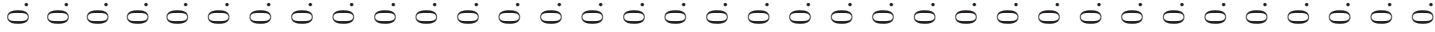

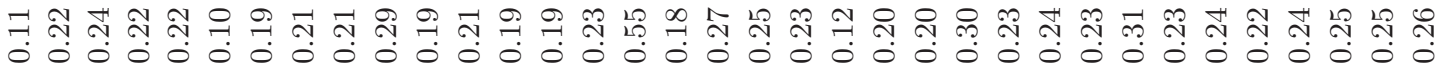

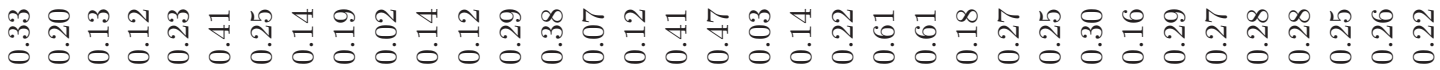
궁

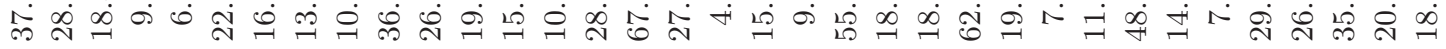

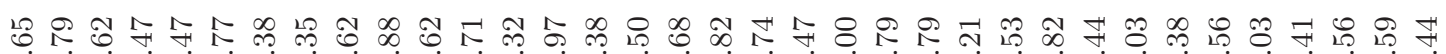

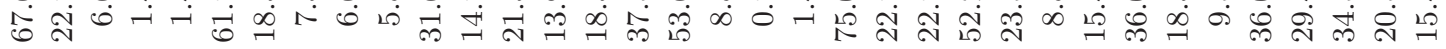

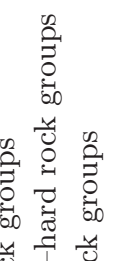

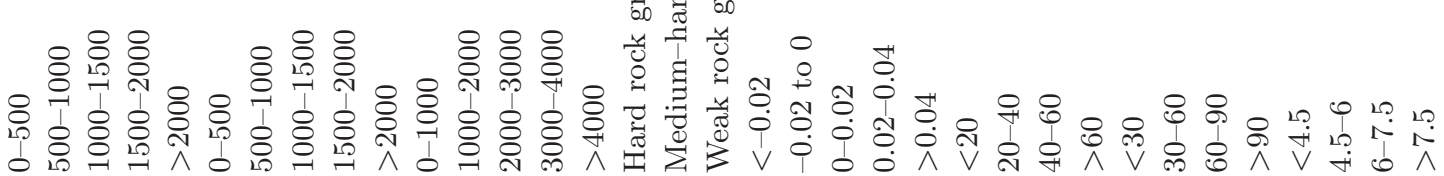

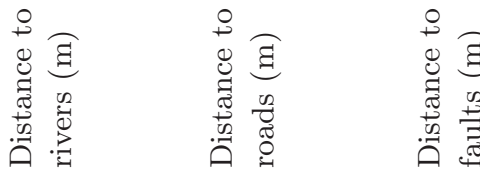

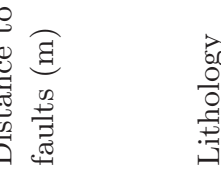
字 旨 $\vec{\sigma}$ E 


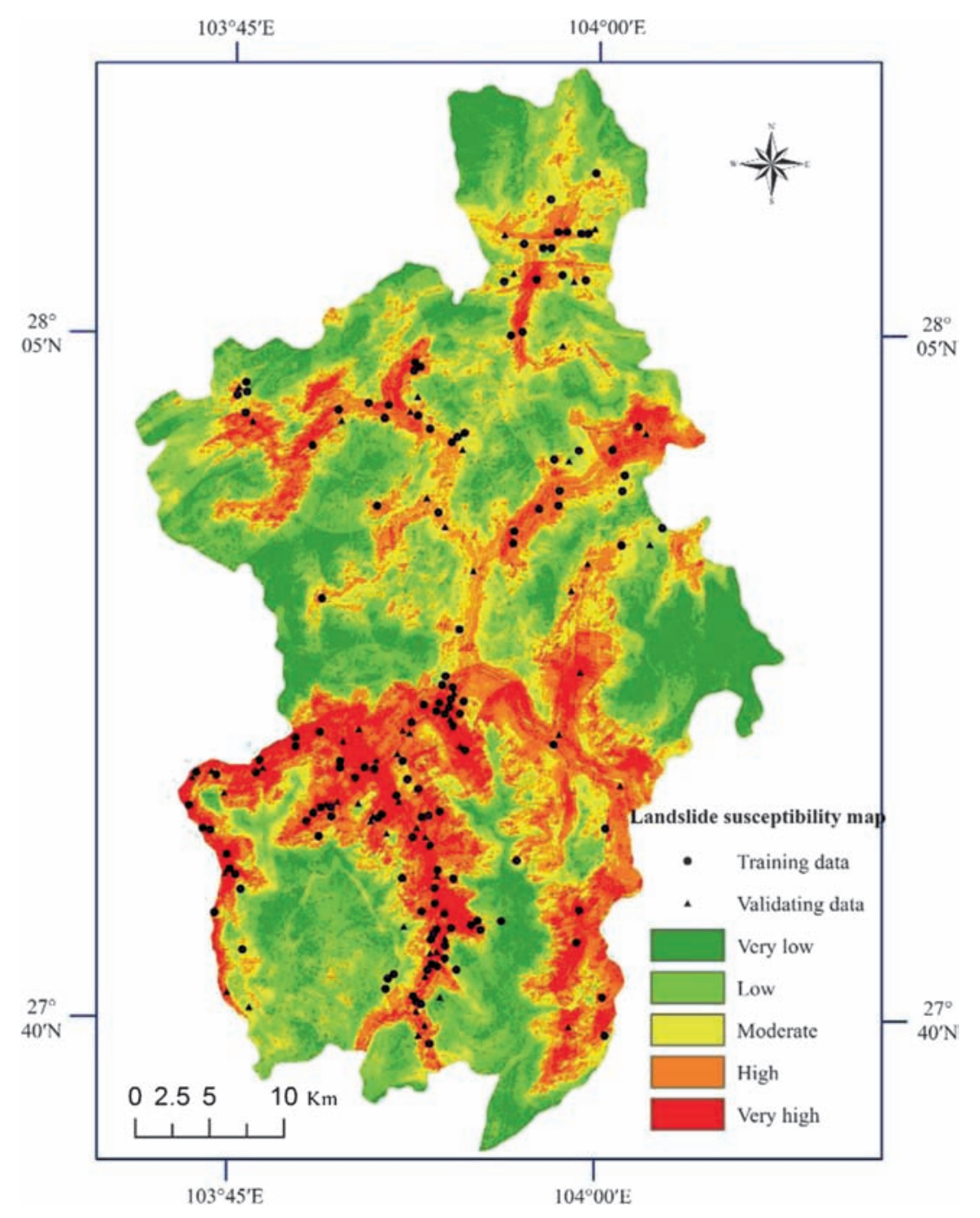

Figure 3. Landslide susceptibility map derived from the EBF model.

also has a clear influence on landslides, because at a distance of $<500 \mathrm{~m}$ the contrast is much higher than for the other classes, indicating a lower probability of landslides further away from the roads. In the case of the relationship between landslide occurrence and distance from faults, the weight value is higher in the class $3000-4000 \mathrm{~m}$. The influence of lithology is also very evident as the contrast is highest for the lithological unit of weak rocks. In the case of NDVI, the class $>0.04$ have higher values, indicating that the probability of occurrence of landslide in this normalized difference vegetation index is high. Most of the landslides are located at $>60$ class for STI as the value is highest here. Relation between SPI, and TWI and landslide probability showed that $30-60$ and $<4.5$ classes have highest weight value, respectively.

In this study, the final calculated LSI values of the area for WoE model range from about -38.454 to 42.046. The LSI on the produced maps was grouped into five classes (very low, low, moderate, high, and very high) (figure 4) using the natural break method. From the output of analysis carried out using the ArcGIS 10.0 (figure 5b), it was found that $19.23 \%$ of the study area was placed in the group with very low susceptibility. Low, moderate and high susceptibility landslide classes comprised of $27.81 \%, 22.63 \%$, and $17.97 \%$ of the area, respectively. In all, $12.36 \%$ of the region was placed in the class with very high landslide susceptibility. It can be observed from figure 5 (b) that $1.03 \%$ and $6.19 \%$ of the total landslides fall in the very low and low susceptibility zones respectively. Moderate, high, and very high susceptible zones represent $14.95 \%$, $29.90 \%$, and $47.94 \%$ of the landslides, respectively.

\subsection{Validation of the landslide susceptibility maps}

A proper validation is necessary to make a certain landslide susceptibility map for any area (Youssef 2015). To do this validation, the area under curve (AUC) method was used in this research 


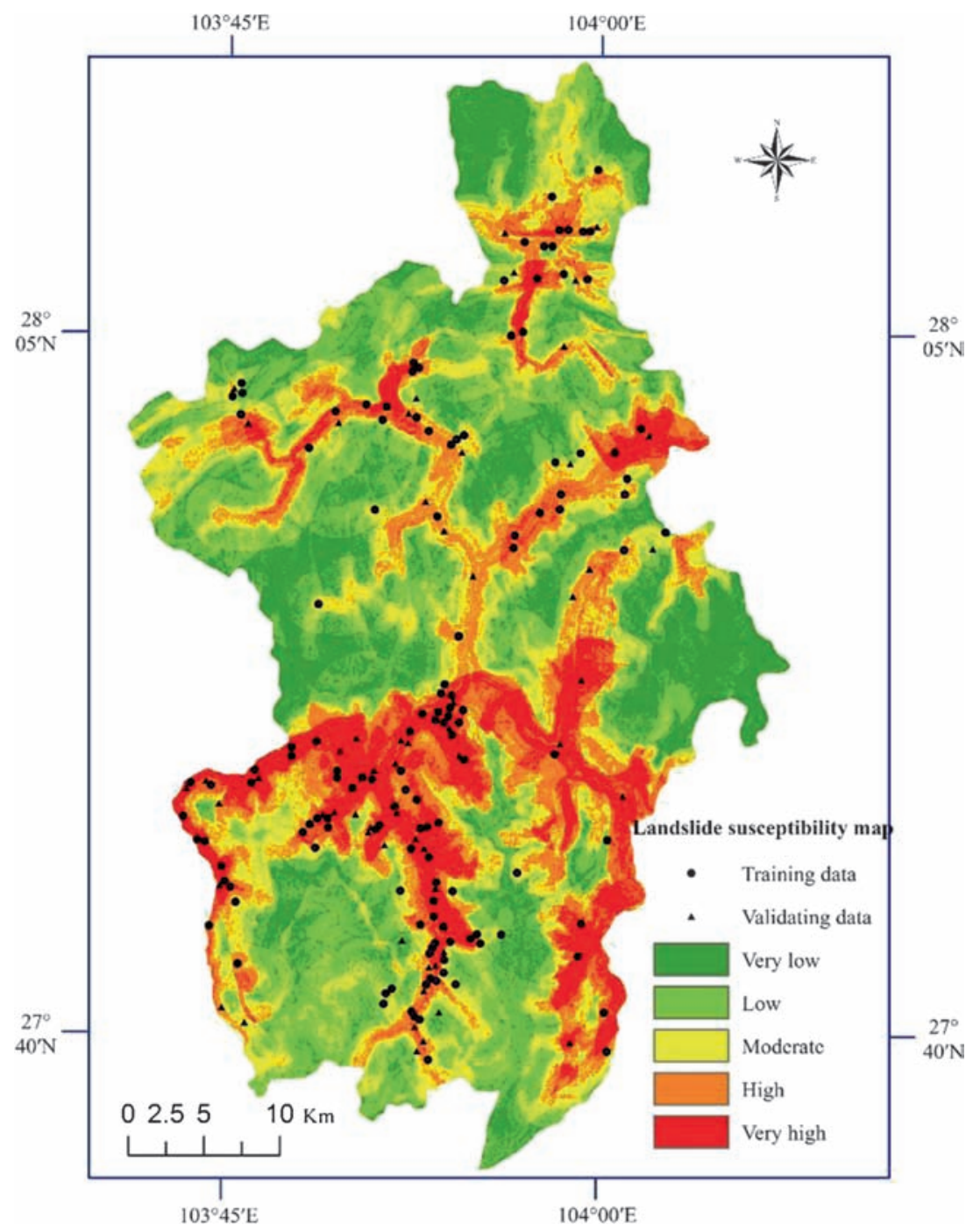

Figure 4. Landslide susceptibility map derived from the WoE model.
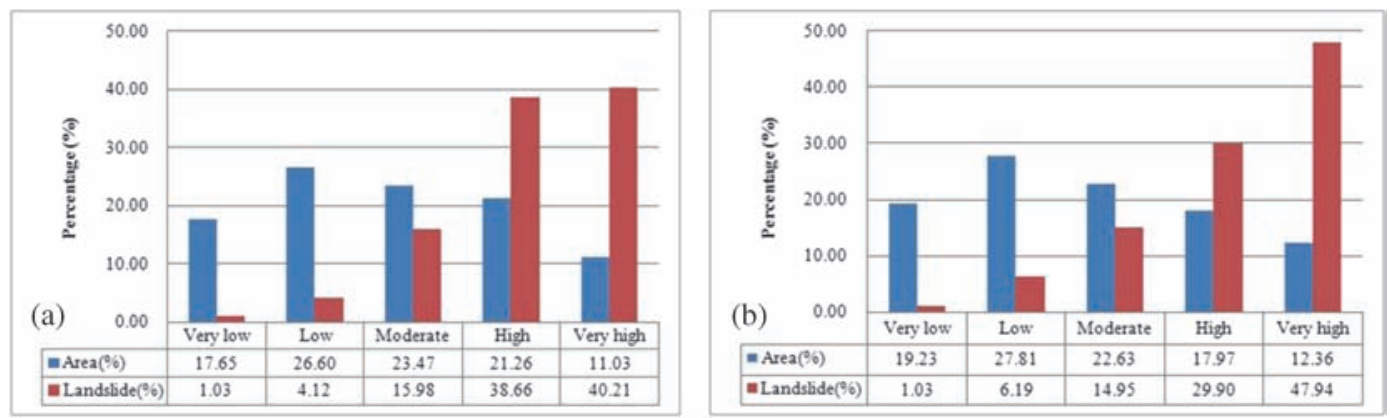

Figure 5. Histograms representing the distribution of observed landslides falling into various susceptibility classes of different landslide susceptibility zonation maps: (a) EBF model and (b) WoE model.

(Chung and Fabbri 2003; Van Westen et al. 2003; Yesilnacar and Topal 2005; Intarawichian and Dasananda 2011; Kayastha et al. 2013b). This method works by creating specific rate curve which explains percentage of known landslides that fall into each defined level of susceptibility rank and displays as the cumulative frequency diagram (Intarawichian and Dasananda 2011). The specific rate curves can be divided into success rate curve and prediction rate curve (Chung and Fabbri 2003). The success rate curve is based on a comparison of the susceptibility map with the landslides used 

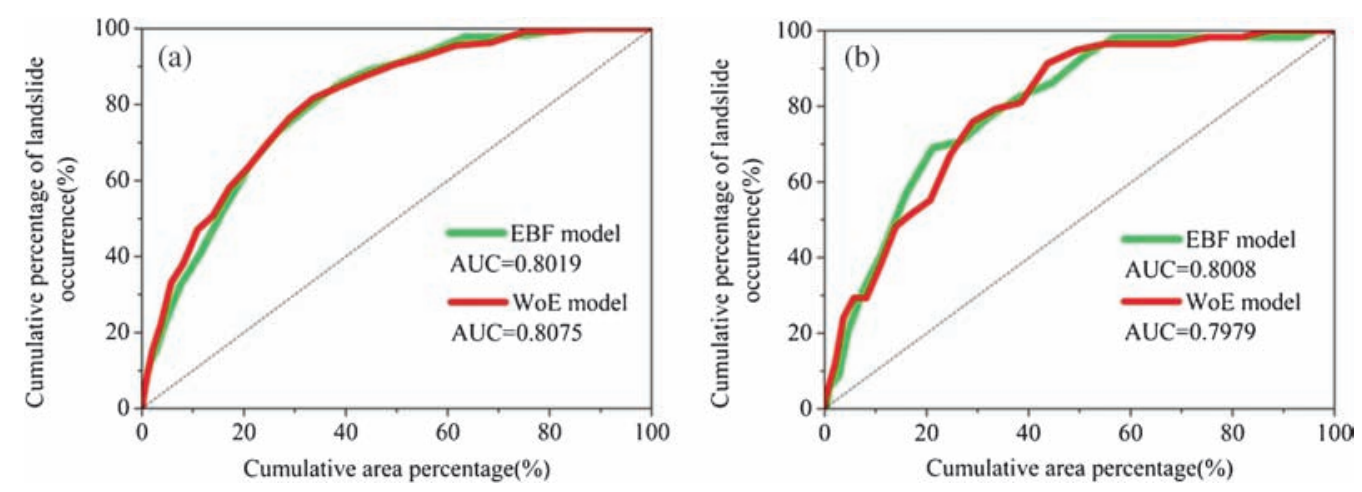

Figure 6. AUC representing quality model. (a) Success rate curve and (b) prediction rate curve.

in modelling. The prediction rate curve can be created by the validation landslide inventory (Pradhan and Kim 2014). In rate curve, the $y$ axis is considered as the cumulative percentage of observed landslide occurrences in different susceptibility classes and the $x$ axis corresponds to the cumulative percentage of the area of the susceptibility classes (Chung and Fabbri 2003; Intarawichian and Dasananda 2011). The area under the curve (AUC) represents prediction accuracy of the susceptibility map qualitatively, in which larger area means higher accuracy achieved (Intarawichian and Dasananda 2011).

In this study, both success rate and prediction rate curves have been used for validation is shown in figure 6. The success rate curves of EBF and WoE models shown in figure 6(a), indicate that the first $10 \%$ of the area of the susceptibility classes can explain about $38 \%, 44 \%$ of all used landslides (out of 136 events), respectively. The first about $80 \%$ for EBF and WoE models can accommodate all known landslides. Similarly, the prediction rate curves (figure $6 \mathrm{~b}$ ) indicate that the first $10 \%$ of the area of the susceptibility classes can explain about $35 \%, 34 \%$ of all used landslides (out of 58 events), respectively. The first about $95 \%$ for $\mathrm{EBF}$ and $\mathrm{WoE}$ models can accommodate all known landslides. In the success rate method, the AUC values for the EBF and WoE models are 0.8019 and 0.8075, respectively. In the prediction rate method, the AUC values for EBF and WoE models are 0.8008 and 0.7979 , respectively. It can be concluded that both the success rate and prediction rate curves show values above 0.8 which represent reasonable models for landslide susceptibility mapping of the study area.

\section{Conclusions}

In this study, both evidential belief function (EBF) and weights of evidence (WoE) models to estimate areas susceptible to landslides for the Daguan
County of Zhaotong city, China, using GIS has been presented. The relationship between a landslide occurrence and the identified 14 conditioning factors such as slope angle, slope aspect, general curvature, plan curvature, profile curvature, altitude, distance to rivers, distance to roads, distance to faults, lithology, normalized difference vegetation index (NDVI), sediment transport index (STI), stream power index (SPI), and topographic wetness index (TWI) is discussed. The selection of the 14 conditioning landslide factors, based on consideration of relevance, availability, and scale of data that was available for the study area, is relative and subjective, and can be improved in future research. Before susceptibility analysis, of the total 194 identified landslide locations in the study area, 136 $(70 \%)$ were used as training data and the remaining $58(30 \%)$ were used for validation goals. The area under the rate curve quantitatively indicates the performance of the susceptibility maps. The results show that the EBF model has a success rate of $80.19 \%$ and predictive accuracy of $80.08 \%$ and WoE model has success rate of $80.75 \%$ and predictive accuracy of $79.79 \%$. The results showed that both landslide susceptibility maps obtained were successful. However, in comparison with WoE model or other spatial data integration models, the EBF model can support a series of mass functions including belief, disbelief, uncertainty and plausibility. Hence, the results can adequately represent quantitative relationships between landslide occurrences and multiple spatial data layers by modelling the degree of uncertainty (Park 2011; Lee et al. 2013). The WoE model is restricted by the assumption on conditional independence. Nevertheless, the WoE model can provide results easy to interpret, and spatial patterns with complex geometries can be modelled with the same computational effort as simple patterns with simple geometry (Neuhäuser and Terhorst 2007). The two models employed in this study area showed reasonably good accuracy in predicting the landslide susceptibility. Meanwhile, it can be observed that 
the landslide occurrence potential map produced by the WoE method is a little bit highly believable, because the method's very high landslide occurrence potential classes correctly predicted more landslides. The landslide susceptibility map presented in this study can be a good source for the decision makers, managers, urban planners, engineers, and land-use developers. Also, it is worth mentioning that a similar method can be used elsewhere where the same geological and topographical feature prevails.

\section{Acknowledgements}

The authors would like to express their gratitude to everyone who provided assistance for the present study. The study is jointly supported by the National Program on Key Basic Research Project (Grant No. 2015CB251601) and the State Key Program of National Natural Science of China (Grant No. 41430643). The authors would also like to acknowledge the two anonymous reviewers and the editor for their helpful comments on the earlier version of the manuscript.

\section{References}

Agterberg F P, Bonham-Carter G F, Cheng Q and Wright D F 1993 Weights of evidence modeling and weighted logistic regression for mineral potential mapping; Comput. Geol. 25 13-32.

Akgun A, Dag S and Bulut F 2008 Landslide susceptibility mapping for a landslide-prone area (Findikli, NE of Turkey) by likelihood-frequency ratio and weighted linear combination models; Environ. Geol. 54(6) 1127-1143.

Al-sharif A A and Pradhan B 2015 Spatio-temporal prediction of urban expansion using bivariate statistical models: Assessment of the efficacy of evidential belief functions and frequency ratio models; Appl. Spatial Analysis and Policy 1-19, doi: 10.1007/S12061-015-9147-1.

Althuwaynee O F, Pradhan B and Lee S 2012 Application of an evidential belief function model in landslide susceptibility mapping; Comput. Geosci. 44 120-135.

Amiri M A, Karimi M and Sarab A A 2014 Hydrocarbon resources potential mapping using the evidential belief functions and GIS, Ahvaz/Khuzestan Province, southwest Iran; Arabian J. Geosci. 8(6) 3929-3941.

Armaş I 2012 Weights of evidence method for landslide susceptibility mapping; Prahova Subcarpathians, Romania; Nat. Hazards 60(3) 937-950.

Awasthi A and Chauhan S S 2011 Using AHP and Dempster-Shafer theory for evaluating sustainable transport solutions; Environmental Modelling \& Software 26(6) 787-796.

Ayalew L, Yamagishi H, Marui H and Kanno T 2005 Landslides in Sado Island of Japan: Part II. GIS-based susceptibility mapping with comparisons of results from two methods and verifications; Eng. Geol. 81(4) 432-445.

Bai S B, Wang J, Lü G N, Zhou P G, Hou S S and Xu S N 2010 GIS-based logistic regression for landslide susceptibility mapping of the Zhongxian segment in the Three Gorges area, China; Geomorphology 115(1) 23-31.
Bednarik M, Magulova B, Matys M and Marschalko M 2010 Landslide susceptibility assessment of the KralovanyLiptovsky Mikulas railway case study; Phys. Chem. Earth Parts $A / B / C$ 35(3-5) 162-171.

Bonham-Carter G F, Agterberg F P and Wright D F 1988 Integration of geological datasets for gold exploration in Nova Scotia; Digital Geologic and Geographic Information Systems, pp. 15-23.

Bui D T, Pradhan B, Lofman O, Revhaug I and Dick O B 2012 Spatial prediction of landslide hazards in Hoa Binh province (Vietnam): A comparative assessment of the efficacy of evidential belief functions and fuzzy logic models; Catena 96 28-40.

Carranza E J M, Van Ruitenbeek F J A, Hecker C, van der Meijde M and van der Meer F D 2008 Knowledge-guided data-driven evidential belief modeling of mineral prospectivity in Cabo de Gata, SE Spain; Int. J. Appl. Earth Observ. Geoinf. 10(3) 374-387.

Carranza E, Woldai T and Chikambwe E 2005 Application of data-driven evidential belief functions to prospectivity mapping for aquamarine-bearing pegmatites, Lundazi district, Zambia; Nat. Resour. Res. 14(1) 47-63.

Chauhan S, Sharma M, Arora M and Gupta N 2010 Landslide susceptibility zonation through ratings derived from artificial neural network; Int. J. Appl. Earth Observ. Geoinf. 12 340-350.

Choi J, Oh H J, Lee H J, Lee C and Lee S 2012 Combining landslide susceptibility maps obtained from frequency ratio, logistic regression, and artificial neural network models using ASTER images and GIS; Eng. Geol. 124 12-23.

Chung C J F and Fabbri A G 2003 Validation of spatial prediction models for landslide hazard mapping; Nat. Hazards 30(3) 451-472.

Conforti M, Aucelli P P, Robustelli G and Scarciglia F 2011 Geomorphology and GIS analysis for mapping gully erosion susceptibility in the Turbolo stream catchment (northern Calabria, Italy); Nat. Hazards 56(3) 881-898.

Dahal R K, Hasegawa S, Nonomura A, Yamanaka M, Masuda T and Nishino K 2008 GIS-based weights-ofevidence modelling of rainfall-induced landslides in small catchments for landslide susceptibility mapping; Environ. Geol. 54(2) 311-324.

Daneshvar M R M 2014 Landslide susceptibility zonation using analytical hierarchy process and GIS for the Bojnurd region, northeast of Iran; Landslides 11(6) 1079-1091.

Davis J D and Sims S M 2013 Physical and maximum entropy models applied to inventories of hillslope sediment sources; J. Soil Sediments 13(10) 1784-1801.

Demir G, Aytekin M, Akgün A, İkizler S B and Tatar O 2013 A comparison of landslide susceptibility mapping of the eastern part of the North Anatolian Fault Zone (Turkey) by likelihood-frequency ratio and analytic hierarchy process methods; Nat. Hazards 65(3) 1481-1506.

Dempster A P 1967 Upper and lower probabilities induced by a multivalued mapping; Ann. Math. Stat. 325339 .

Devkota K C, Regmi A D, Pourghasemi H R, Yoshida K, Pradhan B and Ryu I C et al. 2013 Landslide susceptibility mapping using certainty factor, index of entropy and logistic regression models in GIS and their comparison at Mugling-Narayanghat road section in Nepal Himalaya; Nat. Hazards 65(1) 135-165.

Duman T Y, Can T, Gokceoglu C, Nefeslioglu H A and Sonmez H 2006 Application of logistic regression for landslide susceptibility zoning of Cekmece area, Istanbul, Turkey; Environ. Geol. 51(2) 241-256. 
Ercanoglu M and Gokceoglu C 2002 Assessment of landslide susceptibility for a landslide-prone area (north of Yenice, NW Turkey) by fuzzy approach; Environ. Geol. 41(6) 720-730.

Ercanoglu M, Gokceoglu C and Van Asch T W 2004 Landslide susceptibility zoning north of Yenice (NW Turkey) by multivariate statistical techniques; Nat. Hazards 32(1) 1-23.

Ercanoglu M and Temiz F A 2011 Application of logistic regression and fuzzy operators to landslide susceptibility assessment in Azdavay (Kastamonu, Turkey); Environ. Earth Sci. 64(4) 949-964.

Ghosh S, Van Westen C J, Carranza E J M, Ghoshal T B, Sarkar N K and Surendranath M 2009 A quantitative approach for improving the BIS (Indian) method of medium-scale landslide susceptibility; J. Geol. Soc. India 74(5) 625-638.

Grozavu A, Plescan S, Patriche C V, Margarint M C and Rosca B 2013 Landslide susceptibility assessment: GIS application to a complex mountainous environment; In: The Carpathians: Integrating nature and society towards sustainability, Environ. Sci. Eng., pp. 31-44.

Guettouche M S 2013 Modeling and risk assessment of landslides using fuzzy logic: Application on the slopes of the Algerian Tell (Algeria); Arabian J. Geosci. 6 3163-3173.

Guzzetti F, Carrara A, Cardinali M and Reichenbach P 1999 Landslide hazard evaluation: A review of current techniques and their application in a multi-scale study, central Italy; Geomorphology 31(1) 181-216.

Intarawichian N and Dasananda S 2011 Frequency ratio model based landslide susceptibility mapping in lower Mae Chaem watershed, northern Thailand; Environ. Earth Sci. 64(8) 2271-2285.

Jaafari A, Najafi A, Pourghasemi H R, Rezaeian J and Sattarian A 2014 GIS-based frequency ratio and index of entropy models for landslide susceptibility assessment in the Caspian forest, northern Iran; Int. J. Environ. Sci. Tech. 11(4) 909-926.

Kannan M, Saranathan E and Anabalagan R 2013 Landslide vulnerability mapping using frequency ratio model: A geospatial approach in Bodi-Bodimettu Ghat section, Theni district, Tamil Nadu, India; Arabian J. Geosci. 6(8) 2901-2913.

Kanungo D P, Arora M K, Gupta R P and Sarkar S 2008 Landslide risk assessment using concepts of danger pixels and fuzzy set theory in Darjeeling Himalayas; Landslides 5(4) 407-416.

Kanungo D P, Sarkar S and Sharma S 2011 Combining neural network with fuzzy, certainty factor and likelihood ratio concepts for spatial prediction of landslides; Nat. Hazards 59(3) 1491-1512.

Kayastha P, Dhital M R and De Smedt F 2013a Application of the analytical hierarchy process (AHP) for landslide susceptibility mapping: A case study from the Tinau watershed, west Nepal; Comput. Geosci. 52 398-408.

Kayastha P, Dhital M R and De Smedt F 2013b Evaluation of the consistency of landslide susceptibility mapping: A case study from the Kankai watershed in east Nepal; Landslides 10(6) 785-799.

Kayastha P, Dhital M R and De Smedt F 2012 Landslide susceptibility mapping using the weight of evidence method in the Tinau watershed, Nepal; Nat. Hazards 63(2) 479-498.

Komac M 2006 A landslide susceptibility model using the analytical hierarchy process method and multivariate statistics in perialpine Slovenia; Geomorphology 74(1) $17-28$.
Kritikos T and Davies T 2014 Assessment of rainfallgenerated shallow landslide/debris-flow susceptibility and runout using a GIS-based approach: Application to western southern Alps of New Zealand; Landslides, pp. $1-25$.

Lee S 2004 Application of likelihood ratio and logistic regression models to landslide susceptibility mapping using GIS; Environ. Manag. 34(2) 223-232.

Lee S, Choi J and Min K 2002 Landslide susceptibility analysis and verification using the Bayesian probability model; Environ. Geol. 43(1-2) 120-131.

Lee S, Hwang J and Park I 2013 Application of data-driven evidential belief functions to landslide susceptibility mapping in Jinbu, Korea; Catena 100 15-30.

Lee S and Min K 2001 Statistical analyses of landslide susceptibility at Yongin, Korea; Environ. Geol. 40 10951113.

Lee S and Oh H J 2012 Ensemble-based landslide susceptibility maps in Jinbu area, Korea; In: Terrigenous mass movements (Springer: Berlin Heidelberg), pp. 193220.

Lee S and Pradhan B 2007 Landslide hazard mapping at Selangor, Malaysia using frequency ratio and logistic regression models; Landslides 4(1) 33-41.

Lee S and Pradhan B 2006 Probabilistic landslide hazards and risk mapping on Penang Island, Malaysia; J. Earth Syst. Sci. 115 661-672.

Liu C, Li W, Wu H, Lu P, Sang K and Sun W et al. 2013 Susceptibility evaluation and mapping of China's landslides based on multi-source data; Nat. Hazards 69(3) 1477-1495.

Liu Y, Cheng Q, Xia Q and Wang X 2015 The use of evidential belief functions for mineral potential mapping in the Nanling belt, South China; Front. Earth Sci. 9(2) 342-354.

Ma F, Wang J, Yuan R, Zhao H and Guo J 2013 Application of analytical hierarchy process and least-squares method for landslide susceptibility assessment along the Zhong-Wu natural gas pipeline, China; Landslides 10(4) 481-492.

Mihaela C, Martin B, Marta C J and Marius V 2011 Landslide susceptibility assessment using the bivariate statistical analysis and the index of entropy in the Sibiciu Basin (Romania); Environ. Earth Sci. 63 397-406.

Moore I D, O'loughlin E M and Burch G J 1988 A contourbased topographic model for hydrological and ecological applications; Earth Surface Processes and Landforms 13(4) 305-320.

Nefeslioglu H A, Duman T Y and Durmaz S 2008 Landslide susceptibility mapping for a part of tectonic Kelkit Valley (Eastern Black Sea region of Turkey); Geomorphology 94(3) 401-418.

Neuhäuser B and Terhorst B 2007 Landslide susceptibility assessment using 'weights-of-evidence' applied to a study area at the Jurassic escarpment (SW Germany); Geomorphology 86(1) 12-24.

Ozdemir A and Altural T 2013 A comparative study of frequency ratio, weights of evidence and logistic regression methods for landslide susceptibility mapping: Sultan Mountains, SW Turkey; J. Asian Earth Sci. 64 180-197.

Park N W 2011 Application of Dempster-Shafer theory of evidence to GIS-based landslide susceptibility analysis; Environ Earth Sci. 62(2) 367-376.

Park S, Choi C, Kim B and Kim J 2013 Landslide susceptibility mapping using frequency ratio, analytic hierarchy process, logistic regression, and artificial neural network methods at the Inje area, Korea; Environ. Earth Sci. 68 1443-1464. 
Pourghasemi H R, Pradhan B, Gokceoglu C and Moezzi K D 2012a Landslide susceptibility mapping using a spatial multi-criteria evaluation model at Haraz watershed, Iran; In: Terrigenous mass movements (Springer: Berlin Heidelberg), pp. 23-49.

Pourghasemi H R, Pradhan B and Gokceoglu C 2012b Application of fuzzy logic and analytical hierarchy process (AHP) to landslide susceptibility mapping at Haraz watershed, Iran; Nat. Hazards 63 965-996.

Pourghasemi H R, Moradi H R and Aghda S F 2013 Landslide susceptibility mapping by binary logistic regression, analytical hierarchy process and statistical index models and assessment of their performances; Nat. Hazards 69(1) 749-779.

Prabu S and Ramakrishnan S S 2009 Combined use of socioeconomic analysis, remote sensing and GIS data for landslide hazard mapping using ANN; J. Indian Soc. Remote Sens. 37(3) 409-421.

Pradhan A M S and Kim Y T 2014 Relative effect method of landslide susceptibility zonation in weathered granite soil: A case study in Deokjeok-ri Creek, South Korea; Nat. Hazards 72(2) 1189-1217.

Pradhan B, Abokharima M H, Jebur M N and Tehrany M S 2014 Land subsidence susceptibility mapping at Kinta Valley (Malaysia) using the evidential belief function model in GIS; Nat. Hazards 73(2) 1019-1042.

Pradhan B and Buchroithner M F 2010 Comparison and validation of landslide susceptibility maps using an artificial neural network model for three test areas in Malaysia; Environ. Eng. Geosci. 16(2) 107-126.

Pradhan B and Youssef A M 2010 Manifestation of remote sensing data and GIS on landslide hazard analysis using spatial-based statistical models; Arabian J. Geosci. 3(3) 319-326.

Qiao W, Li W and Zhang X 2014 Characteristic of water chemistry and hydrodynamics of deep karst and its influence on deep coal mining; Arabian J. Geosci. 7(4) 1261-1275.

Raman R and Punia M 2012 The application of GIS-based bivariate statistical methods for landslide hazards assessment in the upper Tons river valley, Western Himalaya, India; Georisk: Assessment and Management of Risk for Engineered Systems and Geohazards 6(3) 145-161.

Regmi A D, Devkota K C, Yoshida K, Pradhan B, Pourghasemi H R, Kumamoto T and Akgun A 2014 Application of frequency ratio, statistical index, and weights-of-evidence models and their comparison in landslide susceptibility mapping in Central Nepal Himalaya; Arabian J. Geosci. 7(2) 725-742.

Regmi N R, Giardino J R and Vitek J D 2010 Modeling susceptibility to landslides using the weight of evidence approach: Western Colorado, USA; Geomorphology 115(1) $172-187$.

Saadatkhah N, Kassim A and Lee L M 2014 Susceptibility assessment of shallow landslides in Hulu Kelang area, Kuala Lumpur, Malaysia using analytical hierarchy process and frequency ratio; Geotech. Geolog. Eng. 33(1) $43-57$.

Saha A K, Gupta R P, Sarkar I, Arora M K and Csaplovics E 2005 An approach for GIS-based statistical landslide susceptibility zonation with a case study in the Himalayas; Landslides 2 61-69.

Sang K 2013 Landslide disaster data statistics and analysis in China during nearly 60 years; Sci. Technol. Commun. 10109.

Saponaro A, Pilz M, Wieland M, Bindi D, Moldobekov B and Parolai S 2014 Landslide susceptibility analysis in data-scarce regions: The case of Kyrgyzstan; Bull. Engg. Geol. Environ., pp. 1-20.
Shafer G 1976 A mathematical theory of evidence (Vol. 1); Princeton University Press, Princeton.

Sharma L P, Patel Nilanchal, Ghose M K and Debnath P 2013 Synergistic application of fuzzy logic and geoinformatics for landslide vulnerability zonation - a case study in Sikkim Himalayas, India; Appl. Geomat. 5 $271-284$.

Sharma L P, Patel N, Ghose M K and Debnath P 2015 Development and application of Shannon's entropy integrated information value model for landslide susceptibility assessment and zonation in Sikkim Himalayas in India; Nat. Hazards 75(2) 1555-1576.

Sharma M and Kumar R 2008 GIS-based landslide hazard zonation: A case study from the Parwanoo area, Lesser and Outer Himalaya, HP, India; Bull. Engg. Geol. Environ. 67(1) 129-137.

Solaimani K, Mousavi S Z and Kavian A 2013 Landslide susceptibility mapping based on frequency ratio and logistic regression models; Arab. J. Geosci. 6 2557-2569.

Suh J, Choi Y, Roh $\mathrm{T}$ D, Lee $\mathrm{H}$ J and Park H D 2011 National-scale assessment of landslide susceptibility to rank the vulnerability to failure of rock-cut slopes along expressways in Korea; Environ. Earth Sci. 63(3) 619-632.

Sujatha E R, Kumaravel P and Rajamanickam G V 2014 Assessing landslide susceptibility using Bayesian probability-based weight of evidence model; Bull. Engg. Geol. Environ. 73(1) 147-161.

Sujatha E R, Rajamanickam G V and Kumaravel P 2012 Landslide susceptibility analysis using probabilistic certainty factor approach: A case study on Tevankarai stream watershed, India; J. Earth Syst. Sci. 121(5) 1337-1350.

Sun L L 2007 Research on geological disaster regionalization based on GIS at Daguan County (Master's thesis, Kunming University of Science and Technology).

Thiam A K 2005 An evidential reasoning approach to land degradation evaluation: Dempster-Shafer theory of evidence; Trans. GIS 9(4) 507-520.

Tsangaratos P and Benardos A 2014 Estimating landslide susceptibility through an artificial neural network classifier; Nat. Hazards 74(3) 1-28.

Van Westen C J, Rengers N and Soeters R 2003 Use of geomorphological information in indirect landslide susceptibility assessment; Nat. Hazards 30(3) 399-419.

Van Westen C J 2000 The modelling of landslide hazards using GIS; Surv. Geophys. 21(2-3) 241-255.

Van Westen C J, Van Asch T W and Soeters R 2006 Landslide hazard and risk zonation - why is it still so difficult? Bull. Engg. Geol. Environ. 65(2) 167-184.

Vijith H and Madhu G 2008 Estimating potential landslide sites of an upland sub-watershed in Western Ghat's of Kerala (India) through frequency ratio and GIS; Environ. Geol. 55(7) 1397-1405.

Wang Q, Li W, Chen W and Bai H 2015 GIS-based assessment of landslide susceptibility using certainty factor and index of entropy models for the Qianyang County of Baoji city, China; J. Earth Syst. Sci. 124(7) 1399-1415.

Yalcin A and Bulut F 2007 Landslide susceptibility mapping using GIS and digital photogrammetric techniques: A case study from Ardesen (NE-Turkey); Nat. Hazards 41(1) 201-226.

Yalcin A 2008 GIS-based landslide susceptibility mapping using analytical hierarchy process and bivariate statistics in Ardesen (Turkey): Comparisons of results and confirmations; Catena 72(1) 1-12.

Yalcin A, Reis S, Aydinoglu A C and Yomralioglu T 2011 A GIS-based comparative study of frequency ratio, analytical hierarchy process, bivariate statistics and logistics 
regression methods for landslide susceptibility mapping in Trabzon, NE Turkey; Catena 85(3) 274-287.

Yang Y 2014 Study on the mechanism and susceptibility of landslide and collapse in Daguan County, Yunnan (Master's thesis, Kunming University of Science and Technology).

Yesilnacar E and Topal T 2005 Landslide susceptibility mapping: A comparison of logistic regression and neural networks methods in a medium scale study, Hendek region (Turkey); Engg. Geol. 79(3) 251-266.

Yilmaz I and Keskin I 2009 GIS based statistical and physical approaches to landslide susceptibility mapping (Sebinkarahisar, Turkey); Bull. Engg. Geol. Environ. 68(4) 459-471.

Yoshimatsu H and Abe S 2006 A review of landslide hazards in Japan and assessment of their susceptibility using an analytical hierarchic process (AHP) method; Landslides 3(2) 149-158.

Youssef A M 2015 Landslide susceptibility delineation in the Ar-Rayth area, Jizan, Kingdom of Saudi Arabia, using analytical hierarchy process, frequency ratio, and logistic regression models; Environ. Earth Sci. 73(12) 84998518.

Youssef A M, Pradhan B, Gaber A F D and Buchroithner M F 2009 Geomorphological hazard analysis along the Egyptian Red Sea coast between Safaga and Quseir; Nat. Hazard Earth Syst. 9 751-766.

Youssef A M, Pradhan B, Sabtan A A and El-Harbi H M 2012 Coupling of remote sensing data aided with field investigations for geological hazards assessment in Jazan area, Kingdom of Saudi Arabia; Environ. Earth Sci. 65(1) 119-130.

Youssef A M, Pradhan B, Jebur M N and El-Harbi H M 2014 Landslide susceptibility mapping using ensemble bivariate and multivariate statistical models in Fayfa area, Saudi Arabia; Environ. Earth Sci., pp. 1-17.

Zare M, Pourghasemi H R, Vafakhah M and Pradhan B 2013 Landslide susceptibility mapping at Vaz Watershed (Iran) using an artificial neural network model: A comparison between multilayer perceptron (MLP) and radial basic function (RBF) algorithms; Arab. J. Geosci. 6(8) 28732888 . 